\title{
La sociopsicohermenéutica de los tipos sociolibidinales
}

The sociopsychohermeneutics of the sociolibidinal types

\author{
Marc Barbeta Viñas \\ Universitat Autònoma de Barcelona \\ marc.barbeta@gmail.com (Espańa)
}

Recibido: 30.01 .2019

Aceptado: 01.12.2019

\section{RESUMEN}

El presente trabajo tiene como objetivo contribuir al desarrollo del enfoque de los tipos sociolibidinales, elaborado originalmente por el sociólogo Alfonso Ortí. Se plantea una actualización de este modelo teórico-metodológico a partir de una propuesta de articulación entre estructuras sociales definidas por la sociología y estructuras afectivas caracterizadas por la psicología dinámica de orientación psicoanalítica. Adicionalmente se presentan algunas notas metodológicas orientadas a la aplicación de la perspectiva sociolibidinal en el seno de investigaciones empíricas. Se concluye la validez metodológica de este enfoque sociopsicohermenéutico dentro de la tradición cualitativa en sociología. La capacidad heurística y reveladora de sus resultados en investigaciones empíricas avalan y contrastan el carácter fecundo del mismo para la investigación social.

\section{PALABRAS CLAVE}

Sociología, afectos, símbolo, discurso, hermenéutica.

\begin{abstract}
The aim of this work is to contribute to the development of the sociolibidinal types approach, originally developed by the sociologist Alfonso Ortí. An update of this theoretical-methodological model is proposed from an articulation between social structures defined by sociology and affective structures characterized by psychoanalytic psychology. In addition, some methodological notes are presented oriented to the application of the sociolibidinal perspective within
\end{abstract}


empirical investigations. We conclude the methodological validity of this sociopsychic-hermeneutical model within the qualitative tradition in sociology. The heuristic capacity and the revelation of its results in the available empirical investigations are contrasted with its fruitful character for social research.

\section{KEY WORDS}

Sociology, affects, symbol, discourse, hermeneutics.

\section{INTRODUCCIÓN}

El presente trabajo tiene como fin contribuir a fundamentar teórico-metodológicamente el enfoque sociopsicohermenéutico. Un modelo de análisis e interpretación de los procesos sociales inspirado en la perspectiva de los tipos sociolibidinales del sociólogo Alfonso Ortí. Este modelo enlaza en un mismo análisis los niveles social y personal-afectivo de los procesos sociales. ${ }^{1}$

Han sido poco habituales dentro de la teoría social propuestas que articulen una teoría sobre las estructuras afectivas de los sujetos con las estructuras sociales donde éstos se inscriben; y que además aporten validez metodológica para la investigación. En algunos casos las teorías elaboradas con miras a la integración entre elementos subjetivos y objetivos no han contado con un abordaje sistemático sobre las estructuras afectivas. En otros casos, se han elaborado teorías con un elevado grado de abstracción que ha restado validez como recurso para el análisis empírico. La propuesta que desarrollamos pretende contribuir a superar estos límites, inscribiéndose en el marco de las recientes aportaciones dedicadas a explorar el diálogo entre sociología y psicoanálisis (Chancer y Andrews, 2014; Clarke, 2006).

Partimos de la hipótesis de la relación entre lo social y lo afectivo; una relación compleja y multidimensional que tiene su comienzo a nivel micro biográfico en la transformación de las estructuras motivacionales primigenias del ser humano en afectos modulados por lo social y la cultura; y su prolongación a nivel macro o meso, tanto en las dinámicas sociales de los afectos como en la dimensión social de éstos. Aunque Freud fue de los primeros en señalar el interés propiamente sociológico del psicoanálisis en cuanto que éste se centra en los fundamentos afectivos de las relaciones del individuo con la sociedad, la

${ }^{1}$ El desarrollo que se propone es una posibilidad de lectura de las enseñanzas de Ortí, entre otras muchas posibles que, sin duda, pueden mejorar y enriquecer la perspectiva que aquí se presenta. El modelo sociolibidinal se ha forjado en décadas de praxis investigadora de su creador. No obstante, no conocemos ningún texto publicado o no donde se exponga la perspectiva que nos ocupa. Las ideas sobre la perspectiva sociolibidinal de Ortí han sido recuperadas de transcripciones de algunas de sus clases dedicadas a este tema y, por otra parte, de algunos de sus esquemas y textos (no publicados) donde se aplica -que no desarrolla- dicha perspectiva. Agradezco a Mario Ortí, Matilde Fernández-Cid y Araceli Serrano el acceso a estos materiales. 
relación entre lo social y lo afectivo, se comparta o no el modelo psicoanalítico, cuenta hoy con un amplio respaldo dentro y fuera de las ciencias sociales, hasta el punto de que en los últimos años se habla del "affective turn" (Blackman y Venn, 2010). ${ }^{2}$ Defendemos entonces que los fenómenos sociales están atravesados por estados afectivos; éstos ejercen influencia sobre las conductas sociales significantes y, por tanto, analizarlos nos acerca a la perspectiva del sentido de los procesos sociales, como hacen las tradiciones comprehensivista, fenomenológica y hermenéutica.

Este interés por la dimensión simbólica de lo social nos permite inscribir el modelo sociolibidinal en la tradición cualitativa en sociología. En particular, en el análisis sociológico del discurso de corte sociohermenéutico (Alonso, 2013; Beltrán, 2016) donde encuentra su referencia más cercana y respecto el que se propone como una vía de ampliación.

Nuestro objetivo específico será desarrollar una propuesta de articulación entre estructuras sociales y afectivas con una dimensión pragmática para la investigación social. Se expondrán aspectos básicos del desarrollo afectivo de la personalidad a la luz de la psicología dinámica actual con miras a reconstruir y actualizar el modelo sociolibidinal de Ortí. Seguidamente se desarrollarán algunos apuntes metodológicos encaminados a orientar su aplicación en el marco de investigaciones empíricas.

\section{EL DESARROLLO AFECTIVO HUMANO: FASES Y POSICIONES EN LA CONFIGURACIÓN DE TIPOS LIBIDINALES ENTENDIDOS COMO ESTRUCTURAS DE RELACIÓN}

La perspectiva sociolibidinal toma como base el estudio que viene realizando el modelo psicoanalítico acerca de los procesos afectivos que constituyen la personalidad. Esta elección teórica supone enfocar algunas de las dimensiones del desarrollo afectivo del ser humano -a lo que el psicoanálisis ha dedicado gran esfuerzo- como elemento central. Ello no supone negar la influencia de otras dimensiones con las que se imbrica (biológico, neuronal), sino centrarse en el proceso de personalización desde un enfoque social y afectivo. Es obvio que el desarrollo de la personalidad trasciende la teoría que esbozamos. La tomamos como referencia, siguiendo a Ortí, siendo conscientes que podría ampliarse el marco teórico. Remitimos al lector a las obras de Freud y sus actualizadores para una más completa visión del modelo de la personalidad que aquí no podemos desarrollar.

Es bien sabido que el psicoanálisis da gran importancia a las vivencias, experiencias y relaciones de la infancia, especialmente el impacto más o menos conflictivo que éstas han tenido para la configuración de la personalidad. Décadas de

2 Atendiendo a objetivos y niveles de análisis también diversos, parte de la psicología y el psicoanálisis (Bateman y Fonagy, 2012), de la sociología (Bericat, 2016; Stets y Turner, 2006) y de la neurología (Damasio, 2018; Panksepp y Biven, 2012) trabajan esta idea. 
investigación a través de observación y análisis de niños y adultos han llevado a una teoría sobre el desarrollo libidinal o afectivo. ${ }^{3}$

Freud (1905) estableció las bases de este desarrollo descubriendo la sexualidad en los niños e identificando una serie de zonas erógenas: áreas del cuerpo (mucosas, genitales) donde se concentra la generación y recepción de estímulos sexuales. Así la libido estaría concentrada en una zona erógena u otra en función de fases en el desarrollo. En el marco de la segunda teoría de las pulsiones, no solamente entraría en juego la libido, entendida como amor, deseo, vida (Eros), sino también los afectos referidos a la agresividad y la muerte (Thanatos). Para la psicología dinámica actual estas fases no se refieren tanto a aspectos psicoevolutivos endógenos, sino más bien a aspectos relacionales que constituyen un conjunto de afectos, ansiedades, conflictos y vivencias. Ello no pretende negar la presencia de excitaciones corporales, pero para evitar los sesgos mecanicistas de la época de Freud, asumimos la tendencia a privilegiar los modos de relación y los estados afectivos resultantes (Tizón, 2018a, 1982; Rodríguez Sutil, 2014; Lorenzer, 1972). Vale añadir que los autores que actualizan la teoría pulsional hablan de emociones primitivas (indagación, deseo, miedo, ira, pena, vínculo, juego) para referirse a los sistemas motivacionales originarios del ser humano (cfr. Panksepp y Biven, 2012; Tizón, 2018a). Sin embargo, independientemente del marco teórico, lo relevante es la forma de desarrollo y elaboración concreta de los deseos y emociones en la constitución del sujeto.

Puede entenderse entonces el desarrollo afectivo como el conjunto de formas con las que nos relacionamos con los otros y con el mundo en tanto que relaciones de objeto. Esto supone afirmar que las cosas y los demás son objeto de pulsiones, motivaciones y deseos de los sujetos, en la medida en que ejercen de referentes de las acciones y/o representaciones de los mismos. Freud (1923) ya había relacionado el carácter del Yo con estos objetos y las fijaciones producidas a lo largo de la biografía de un sujeto. Siguiendo su estela, aunque poniendo en el centro el concepto de Self, con la actual psicología dinámica podemos decir que las relaciones con los objetos externos -tal como entran en relación con un sujeto- tienden a generar objetos internos; eso es, "el sedimento experiencial, representacional que produce en nosotros el conjunto de nuestras relaciones con un objeto externo: el conjunto de ansiedades, sentimientos, ideas con los que nos representamos un objeto externo" (Tizón, 1982: 26).

\footnotetext{
${ }^{3}$ En psicoanálisis la libido como pulsión sexual incluye una tendencia al amor, a la integración y la relación con los otros y las cosas, la vinculación y la vida en general. El uso de términos como libido derivan de la visión energetista del psicoanálisis, en revisión por algunos autores contemporáneos. En un sentido muy cercano ocurre lo mismo con las teorías de las pulsiones, habiendo autores que las defienden y otros que las sustituyen por "emociones primitivas" (véase Coderch, 2010). En la medida en que es un debate que supera los objetivos y posibilidades de este trabajo, vamos a usar los términos y conceptos tal como lo hacen los autores citados. Puede defenderse o no la conveniencia de usar términos como libido, pero en todo caso, puede también usarse el termino afecto, como aquí haremos de forma indistinta, entendiendo que son los afectos aquello que está en juego en los tipos que presentamos.
} 
La estructura de la personalidad, desde este enfoque, se formaría a partir de la interiorización de estas experiencias, vivencias cargadas emocionalmente y fijadas como engramas. Éstas, a modo de objetos internos, irían organizando formas específicas de expresión de deseos y ansiedades, estructurando nuestras significaciones con respecto a la realidad externa, y formando así fantasías básicas. Algunas de ellas serían de tipo consciente pero muchas más adquirirían en el desarrollo una forma preconsciente e inconsciente. La personalidad quedaría marcada por esta estructura fantasmática de significaciones y vivencias internas. En virtud de los procesos de fijación y regresión, pueden persistir afectos, conductas y representaciones propias de momentos anteriores (Tizón, 2018a: 163). Es necesario para nuestra perspectiva insistir en que los actores sociales no se relacionan con objetos externos "en bruto", sino que éstos, sean otros sujetos, grupos, ideas abstractas, objetos... están mediados por las vivencias, deseos y ansiedades vinculadas con la biografía de cada sujeto.

En el marco de la dialéctica entre las necesidades corporales infantiles y los modos de satisfacerlas por el entorno (con mayor o menor grado de frustración para los niños), el primer modo de relación objetal se corresponde con la fase oral. A caballo entre un primer período de indiferenciación (narcisista), en el que el bebé no distingue entre lo propio y lo de afuera, entre el Yo y el no-Yo, y las primeras cargas de objeto, la oralidad se desarrolla a partir de las necesidades alimenticias de la criatura. En Freud (1905) la pulsión sexual se satisface apuntalada en la función alimenticia, pero poco a poco toma autonomía de ésta.

Autores más cercanos a un modelo psicosocial, como Erikson (1963), llaman a esta fase oral-sensorial porque en ella no solo se incorporan alimentos y placer, sino también a través de los sentidos (olores, tacto, audición) sensaciones fundamentales para el desarrollo. En esta fase se asientan las bases psicológicas de la incorporación y la capacidad de recibir. Se trata de asimilar psíquicamente las cualidades de los objetos dentro de uno mismo: a través del pecho se adquiere placer, seguridad, calor, contacto con la piel del otro, alimentación, etc. Según este autor son muy relevantes en la oralidad las fantasías básicas de confianza y desconfianza. El predominio de una u otra supone la posibilidad de vivir con confianza los objetos externos, así como el Yo, y sentir la propia capacidad de enfrentar las ansiedades y deseos. La falta de seguridad y confianza, la avidez y la dependencia serian resultantes de ciertas fijaciones orales.

La psicoanalista Melanie Klein estableció la existencia dentro de esta fase oral de las posiciones esquizo-paranoide y maníaco-depresiva. La noción de "posición" es muy relevante para la propuesta sociolibidinal, más si se entiende como estructura de relación. Una posición es una estructura de ansiedades, defensas y emociones básicas que predominan en la vida mental y relacional, tanto en relación con lo interno como con lo externo, en diversos momentos de la vida (Tizón, 2018a: 195). Lo que supone que los elementos de cada posición siguen activos en la personalidad de los sujetos adultos, pudiendo aflorar dadas ciertas condiciones. Así cada posición pondría en funcionamiento un conjunto de fantasías, acciones y reacciones en determinados contextos y situaciones. 
Klein (1946) señala que en la primera posición el bebé proyecta dos fantasías que escinden imaginariamente el pecho materno en tanto objeto parcial: el "pecho bueno", idealizado, tranquilizador, relajante, relacionado con las experiencias placenteras; y el "pecho malo", persecutorio, resultado de la proyección de la propia agresividad y las frustraciones. El bebé pretende introyectar lo vivido como bueno y echar fuera lo malo. Esta posición se relaciona con las estructuras psicóticas, formando parte del desarrollo psíquico "normal".

De forma consecutiva, según Klein, se desarrolla la posición maníacodepresiva en la que el bebé, algo más maduro, consigue integrar al objeto como objeto total. El objeto (la madre o sustituto) se reconoce como "bueno" y "malo" al mismo tiempo, siendo también el momento donde se produce la separación sujeto-objeto. El bebé siente que la madre a veces cuida, está presente y proporciona placer, pero a veces esto no ocurre y genera frustración. Dirige su amor pero también su odio hacia el objeto, y esta ambivalencia tiende a generar una angustia depresiva por haber dañado al objeto y por la posibilidad de perderlo. Así surgen los primeros sentimientos de culpa por haber odiado al objeto y con ellos la posibilidad de reparación. Para la autora estos afectos son clave para un buen desarrollo y poder introyectar los componentes "buenos" de los objetos. Una mala elaboración produce defensas maníacas, en forma de omnipotencia, dominación y sensación de triunfo (Klein, 1957).

Alrededor de los dos años de vida, en el contexto de los estados depresivos, aparece la fase anal en la que, según la teoría clásica, la libido se concentra en la zona rectal del cuerpo, apuntalando la sexualidad (Freud, 1905). Las relaciones de objeto se vinculan con las significaciones derivadas de la actividad excremental, así como del control muscular del conjunto del cuerpo. Por ello Erikson (1963) la llama fase músculo-anal. Es central en ella la pugna entre los deseos del niño y las pautas educativas del entorno: control de esfínteres, higiene, etc. Con la elaboración de estas relaciones emerge en el niño la sensación de autonomía y autocontrol, ganando así en autoestima. Éste muestra ante los demás (los padres) la capacidad de hacerse cargo de lo propio, siendo bien valorado por ello. La teoría clásica atribuye un carácter simbólico a los excrementos, siendo material de intercambio como señal de obediencia y amor a los padres (Freud, 1905: 168-170). Como Freud (1908: 153) ya había observado, en esta fase se juegan los caracteres que tienen relación con la obstinación, el orden, la ley y las normas, la meticulosidad, el control, la capacidad de dar y el ahorro. Pero también puede suceder que el contexto interaccional (la vivencia de unos padres excesivamente rigurosos, exigentes) genere unas relaciones de objeto marcadas por la vergüenza, la duda y el miedo. Los tipos obsesivos se han relacionado con las características anales (Tizón, 2018b; Rodríguez-Sutil, 2014).

La tercera fase es la fálica en términos clásicos, o fálico-motora para autores como Erikson (1963). El órgano central es el pene (falo) tanto para niños como para niñas, alrededor del cual unos y otras desarrollan vivencias, afectos y fantasías. Se suele hablar de falo dada la deformación que entrañan las fantasías en torno al órgano real, marcadas por su función, su poder, el dominio, las capacidades destructivas, "meterse" en el otro, invadir, etc. La agresividad en 
esta fase es muy relevante, se vive como rivalidad, ambición, culpa, hostilidad ante el poder o la autoridad, y la afirmación propia de la misma (Tizón, 1982). La oposición fálico-castrado genera la vivencia de que todo el mundo posee un falo. Sin embargo, al descubrir la falta de falo en las niñas, éstas según la teoría clásica del complejo de Edipo se interrogan acerca de tal hecho, aunque ello ha generado controversia entre perspectivas teóricas (cfr. Butler, 2006). Erikson sitúa esta fase en una trama psicosocial definiéndola a través de los parámetros de la iniciativa y la culpa. Niños y niñas se muestran expansivos en la mostración de sus potenciales personales, en el planteamiento de dudas, descubrimientos, se muestran como "intrusos" en un mundo que quieren conquistar, dominar y en el que quieren reafirmarse.

Seguidamente aparece el llamado periodo de latencia y con el advenimiento de la pubertad se llega a la fase genital. Las vivencias propias de este momento son la ternura, la comunicación con el otro, la productividad y la creatividad. Autores como Tizón (1982: 235) han llamado -en línea con Erikson- a esta fase genital-generativa, definida por una capacidad productiva y generativa, que supone una cierta erotización ("amor, interés") del entorno. La generatividad implica las vivencias asociadas con la capacidad de guiar, orientar, cuidar a las nuevas generaciones y a los demás. Como estructura de relación las personas se insertan y la abandonan en distintas ocasiones durante el transcurso de su vida, dadas las complejidades de la madurez psíquica.

Desde una perspectiva sincrónica, el sadismo y el masoquismo se articulan con las otras estructuras libidinales. Ha sido habitual utilizar en la propuesta sociolibidinal la obra Presentación de Sacher-Masoch de Gilles Deleuze (1967). Esta define dos estructuras sin derivación genética una de la otra y con características diferenciadas: el sádico y el masoquista; y se entienden estas estructuras de carácter como formas de relación cultural con los otros y las cosas. Desde la psicología clínica se han descrito estructuras afectivo-relacionales coincidentes con los caracteres que plantea el filosofo francés (Millon y Davis, 1999).

Añadiremos solamente que siendo estas las bases de los objetos internos primitivos, su desarrollo y articulación específica, según se ha descrito recientemente, tiende a promover estructuras relacionales y afectivas psico(pato) lógicas básicas: estructuras histéricas, fóbico-evitativas, obsesivas, melancólicomaníacas, paranoides, perversas, etc. (Tizón, 2018a, 2018b, 2019a). Futuros desarrollos podrán calibrar la posibilidad de una lectura y uso sociológico de las mismas. 
Figura 1. Tipos libidinales: conflictosy caracteres básicos

\begin{tabular}{|c|c|c|c|}
\hline \multirow{2}{*}{ ORAL } & ESQUIZO-PARANOIDE & \multirow{2}{*}{$\begin{array}{l}\text { (Des)confianza, } \\
\text { (in)seguridad, dependencia, } \\
\text { incorporación, vinculación } \\
\text { (fusional). } \\
\text { Relajación, búsqueda placer, } \\
\text { voracidad, avidez, recepción. }\end{array}$} & $\begin{array}{l}\text { Temor persecutorio, envidia, rabia, } \\
\text { ira, precaución, cautela, huida, } \\
\text { afirmación agresiva, defensivo. }\end{array}$ \\
\hline & MANIACO-DEPRESIVA & & $\begin{array}{l}\text { Pena, nostalgia, celos, culpa, } \\
\text { añoranza, omnipotencia, sensación } \\
\text { triunfo, reparación, creación. }\end{array}$ \\
\hline \multicolumn{2}{|l|}{ ANAL } & \multicolumn{2}{|c|}{$\begin{array}{l}\text { Autonomia vs vergüenza y duda, (auto)control, ritualismo, obsesivo, } \\
\text { posesivo, obstinado, retentivo-expulsivo, ahorrador, ascetico, } \\
\text { donante- avaro, meticuloso, terco, ordenado, normativo, imágenes } \\
\text { excrementales. }\end{array}$} \\
\hline \multicolumn{2}{|c|}{ FÁLICO } & \multicolumn{2}{|c|}{$\begin{array}{l}\text { Iniciativa vs culpa, conquistador, manifestación poder, capacidad } \\
\text { destructiva, rivalidad, ambicioso, disputa autoridad, expansivo, } \\
\text { potencia personal, conquistar, reafirmación, descubridor, imágenes } \\
\text { fálicas. }\end{array}$} \\
\hline \multicolumn{2}{|c|}{ GENITAL-GENERATIVO } & \multicolumn{2}{|c|}{$\begin{array}{l}\text { Generatividad vs estancamiento, creativo, productivo, procreador, } \\
\text { identidad, integridad, erotización mundo, cuidar, guiar al otro; } \\
\text { aislamiento, estancamiento, desesperación. }\end{array}$} \\
\hline \multicolumn{2}{|c|}{ SÁDICO } & \multicolumn{2}{|c|}{$\begin{array}{l}\text { Instructor, irónico, apático, meticuloso, formal, activo, triunfador, } \\
\text { agresivo, dogmático, }\end{array}$} \\
\hline \multicolumn{2}{|c|}{ MASOQUISTA } & \multicolumn{2}{|c|}{$\begin{array}{l}\text { Pasivo, idealista, humoristico, estricto cumplidor normas, educador, } \\
\text { erotiza y exhibe sufrimiento, inseguro, deferente. }\end{array}$} \\
\hline
\end{tabular}

Fuente: elaboración propia a partir de Freud (1905), Erikson (1963), Tizón (1982), Deleuze (1967).

\section{LOS TIPOS SOCIOLIBIDINALES: LA ARTICULACIÓN DE LO AFECTIVO Y LO SOCIO-SIMBÓLICO}

La propuesta de los tipos sociolibidinales se aleja de cualquier explicación psicologista de los fenómenos sociales. Pretende reorientar la idea de un sujeto de deseos universal planteando la existencia de estructuras afectivas distintas para conjuntos también diferentes de contextos y situaciones sociales. La configuración de este modelo pasa por proponer un modo de articulación entre las estructuras socio-simbólicas, de orden colectivo, y las esbozadas estructuras afectivas, de orden personal.

Dentro de la teoría social han habido algunas propuestas de articulación entre estructuras objetivas y subjetivas. Elias (1990) elabora una concepción del carácter social entendiendo los cambios en las estructuras psíquicas a partir de los cambios y evolución de las formaciones socioculturales. Por su parte, el habitus de Bourdieu (1991) relaciona disposiciones con posiciones sociales. Algunos de los críticos seguidores del autor francés le ha dado al habitus un 
carácter múltiple y heterogéneo, con el que define una subjetividad social plural. Se trata de un enfoque contextual-disposicionalista que en algunos aspectos se acerca a los planteamientos que aquí presentamos (Lahire, 2012). También Gerth y Wright Mills (1984) definieron una estructura de carácter básica en la que lo psíquico se vincula con los roles sociales de los sujetos. Más allá de sus innegables virtudes para sociología, estas propuestas adolecen de una teoría que aborde sistemáticamente la estructura afectiva de los individuos. Una cuestión fundamental para el enfoque sociolibidinal, siendo además su aportación particular.

Más próximos a nuestra propuesta están los intentos de integración de los componentes (bio)psico-sociales del ser humano (Pasqualini, 2016). ${ }^{4}$ En esta perspectiva el citado trabajo de Erikson (1963) analiza cómo en una cultura se internalizan las primeras relaciones de objeto. Plantea la posibilidad de tomar como agregado los modos de interiorización similares en cada individuo dentro de un grupo social determinado. Se podrían reconocer así modalidades sociales de relación desde lo afectivo en la vida social. De esta forma sería probable que se configurasen instituciones sociales consecuencia de tales modalidades de reacción afectiva, sin embargo tiende a olvidarse de los contextos sociales macro y presentes.

Desde una perspectiva más sociologizada encontramos la propuesta del $c a$ rácter social de Erich Fromm (1976). Este lo define en base a aquellos elementos comunes del carácter entre individuos pertenecientes a los mismos grupos sociales. Se forjaría en individuos en la medida en que experimentan modos de vida comunes a los miembros de su grupo, determinados por unas condiciones de existencia objetivas. Para Fromm (1976: 92) el carácter social sería la correa de transmisión entre la estructura socioeconómica, y las ideas y motivaciones comunes de los individuos en un momento histórico dado.

Estos trabajos, no obstante, no problematizan suficientemente el proceso de integración entre estructuras sociales y afectivas en el que se basan. Su utilización como herramienta para la investigación social supondría el recurso a abstracciones psicosociológicas poco fundadas. Nos llevarían a afirmar que todos los individuos de un grupo social o cultural deberían tener un "carácter determinado" en común -en Fromm- o una "modalidad social" de relación de objeto -en Erikson- debido a haber estado sujetos a una socialización primaria en las mismas condiciones objetivas. Así Fromm (1977) atribuye un "carácter autoritario" al conjunto de la clase media alemana, con un correlato afectivo determinado, en su explicación del nazismo, manteniendo el mismo esquema en la explicación del capitalismo (Brown, 1959). Sin embargo, sería poco legítimo imputar este carácter psicológico a todos y cada uno de los individuos de un grupo social, por ejemplo la clase media alemana. Probablemente no sea posible probar que todos

${ }^{4}$ Un gran número de trabajos han vinculado teoría social y psicoanálisis en lo referente a la cuestión aquí propuesta: desde la escuela de Frankfurt, W. Reich, K. Horney y A. Kardiner, los trabajos antropológicos de G. Roheim, así como los desarrollos más cercanos a nuestro modelo como el sociopsicoanálisis de G. Mendel, las intuiciones de N. Brown y alguna de las ideas expresadas por G. Deleuze y F. Guattari. Nos centramos, sin embargo, en aquellas propuestas más cercanas al objeto de estudio en cuestión y que dialogan en mayor medida con la sociología 
ellos (individuos empíricos reales) respondan homogéneamente a un determinado carácter. Tampoco sería legítimo trasponer modelos psicológicos, propios de un individuo real, a entes colectivos como grupos o clases sociales, suponiendo por ello que las entidades sociales en sí mismas poseen estructuras afectivas.

Esta perspectiva basada en la integración supondría una correspondencia "perfecta" entre elementos explicativos sociales y personal-afectivos. Cada elemento afectivo, de carácter permanente y fijo quedaría perfectamente imbricado y reforzado por elementos socio-culturales y a la inversa (Devereux, 1972). Un esquema de dudosa validez para el análisis de sociedades actuales, plurales y heterogéneas social, cultural y personalmente, así como desde los conocimientos actuales de la sociología y la psicología dinámica. Cabría preguntarse lo siguiente: ¿es posible y cómo se aborda cierta diversidad de vivencias afectivas entre miembros de un mismo grupo social respecto a un mismo fenómeno? Y, por otra parte ¿cabe una vivencia afectiva similar respecto a un fenómeno entre miembros de grupos sociales distintos?

La evidencia empírica nos dice que sí a las anteriores cuestiones, pero modelos como los de Fromm (1976) tendrían problemas para dar cuenta de estos interrogantes. Para superar el mecanicismo de su propuesta sería necesario explicitar cómo el nivel socio-cultural influye sobre los procesos afectivos y del carácter. Una cuestión que debería esclarecerse, como sugiere Lahire (2012), no solamente en relación al proceso de socialización primaria de los individuos (pasado incorporado), sino en lo relativo a los aspectos contextuales e intersubjetivos presentes, capaces de convocar determinadas experiencias pasadas. Así las formas de incorporación de las vivencias del mundo en función de la posición social de los sujetos deberían entenderse desde un doble punto de vista: diacrónico y biográfico-afectivo, por una parte, sincrónico y colectivo, por otra.

Una vía para comprender la cuestión planteada la podemos encontrar en la concepción cognitivo-afectiva del simbolismo (Barbeta Viñas, 2015b). De acuerdo con esta perspectiva un símbolo sería la síntesis entre los afectos de carácter personal y los elementos socio-culturales que forman los llamados universos simbólicos de sujetos y grupos sociales (Ortí, 1994). Así la formación de símbolos nos remitiría, en un primer nivel estrictamente personal, a la socialización primaria de los sujetos y a sus estructuras afectivas (Furth, 1992; Lorenzer, 1976, 1972). Una de sus dimensiones principales sería el nivel relativo a las estructuras afectivas presentado en el epígrafe anterior.

El segundo nivel haría referencia a la dimensión social y culturalmente dada en un momento histórico de los símbolos. Se trataría de la vertiente sincrónica y cognitiva de los universos simbólicos (formaciones culturales, ideológicas...) entendidos como entidades externas a los sujetos considerados individualmente: les precederían y les vendrían dados socialmente. Serían, no obstante, los mismos sujetos quienes, en el escenario social, contribuirían a configurarlos y desarrollarlos en plena vinculación con las estructuras e instituciones sociales y de poder (Williams, 1994; Berger y Luckmann, 1967). Este carácter simbólico (cultural, ideológico) supondría dotar las relaciones e interacciones sociales de una dimensión comunicativa e intersubjetiva (Geertz, 1973: 88). Lo que equi- 
valdría a decir que los miembros de los grupos sociales constituirían sistemas de representaciones colectivas por los cuales interpretan dichas relaciones y procesos con sentidos sociales específicos, dados unos contextos sociales e históricos.

El punto de síntesis entre ambos niveles sería aquel en el que estas formaciones simbólicas (culturales, ideológicas...) derivadas de contextos sociales e interpersonales evocarían, de forma común en miembros de un grupo social, determinadas proyecciones en una suerte de intersubjetividad afectiva o, como dicen Long y Harney (2013), de "inconsciente asociativo". Unas proyecciones que expresarían la exteriorización en la interacción social, mediante actitudes y discursos, de modos de relación afectiva, deseos y sentimientos de los propios sujetos sociales en su vínculo no siempre consciente con la realidad y los otros (Ortí, 1993: 167). Los sujetos, como señala Tizón (2018a: 82), pueden vivir en estructuras de relación afectiva y no consciente distintas según diferentes momentos vitales, si bien cabe la existencia de dominancias de unas respecto a otras.

La mediación entre elementos sociales y personales que ejercen las formaciones socio-simbólicas puede ser comprendida desde la tesis complementarista de George Devereux (1972: 111-130). Así las relaciones entre las dimensiones socio-culturales y psicológicas se entenderían desde el carácter "instrumental" que unas tienen respecto a las otras. La tesis de la integración, como hemos visto, nos lleva a generalidades un tanto rígidas y abstractas. La idea que proponemos, en cambio, admite una relación de "incertidumbre" entre elementos afectivos y socioculturales. Los elementos sociales y simbólico-culturales deberían "servir" como contexto social para desencadenar, canalizar o brindar la oportunidad de expresión (o inhibición) a los factores de orden afectivo. Este carácter "instrumental" implicaría entender, por una parte, el contexto (sea un grupo social, una posición, un campo o institución social con sus rasgos simbólicos), como elemento habilitador cuando permite "activar" ciertas disposiciones, competencias y sistemas de valores a nivel más consciente, cognitivo y racionalizado (Lahire, 2012). Y por otra parte, la instrumentalidad del contexto haría referencia a su carácter de "facilitador afectivo", permitiendo tanto la expresión no consciente de deseos como el desarrollo de defensas contra la ansiedad y la ambivalencia (Figlio, 2018).

Desde esta perspectiva, la lógica sociolibidinal sería una lógica sobredeterminada en tanto que haría referencia a una pluralidad de elementos operantes en un proceso que admitiría distintas vías o niveles de interpretación (Laplanche y Pontalis, 1993: 411). El modelo sociolibidinal reconocería modos de vinculación específica de lo afectivo con el entorno; eso es, con las condiciones socio-históricas y simbólico-culturales que contribuyen a significar un fenómeno social. Estas condiciones se materializan en la posición social de sujetos y grupos, así como en la construcción intersubjetiva de su realidad. Lo que, como hemos señalado, definiría un contexto socio-simbólico (asignando a un fenómeno determinados valores simbólicos, creencias, normas sociales, hábitos colectivos, etc.), que sería "instrumental" en la medida que facilitara-sobredeterminara una relación de objeto- un tipo específico de proyección o reacción afectiva. Este emergen- 
te afectivo supondría dar un sentido a la vez social y personal a un fenómeno social, dada la forma en que cada sujeto vive internamente (y coincide más o menos con los demás) su relación con la realidad social. Seguimos de cerca a Ortí (1975: LIX) cuando afirma que "mi metodología interpretativa presupone una primacía de la clase - de modo más específico: la situación de clase- sobre la estructura del carácter: la reacción caracterial emergente sería una respuesta a la posición de clase del sujeto determinada al nivel de la clase por las relaciones históricas concretas de la lucha de clases en una formación social dada, y tan solo sobredeterminada emocionalmente, al nivel del individuo, por la formación afectiva básica".

Con esta concepción, por tanto, no se trata de dar cuenta de los fenómenos sociales apelando a la satisfacción directa que los sujetos consiguen en ellos, sea en forma de impulsos biológicos o psíquicos estrictamente individuales. Lo que se propone es abordar la forma "instrumental" y socialmente moldeada de satisfacerlos o expresarlos. El medio social con sus contextos simbólico-culturales e ideológicos se articularía y convocaría las dinámicas afectivas con las que los sujetos viven de forma más o menos común dichos contextos (Ortí, 1979: 9).

No concebimos así una correspondencia necesaria y fija entre posiciones sociales y tipos libidinales concretos: por ejemplo, las relaciones descritas entre el carácter sádico y las clases dominantes, y el carácter masoquista y las clases dominadas (Ortí, 1998: 436). Estas relaciones pueden tener un carácter lógico por consonancia entre los elementos socio-culturales y afectivos. Sin embargo, podría pensarse, siguiendo el ejemplo, en la existencia de grupos sociales en las que sus miembros se muestren dominantes en unos ámbitos, pero dominados en otros. Sería entonces el análisis concreto aquello que establecería la dinámica socio-afectiva concreta en cada caso.

La propuesta sociolibidinal sigue de cerca la idea weberiana de los "tiposideales", de aquí que hablemos de tipos sociolibidinales. Este recurso metodológico nos permite dar cuenta de concepciones ideales abstractas que no se corresponden con la realidad empírica de los individuos. Los tipos refieren, en este caso, a tendencias o modelos de relación afectiva dominante que manifiestan de forma común un conjunto de individuos en un contexto dado. En ningún momento el análisis sociolibidinal representa un análisis individualizado, sino como afirma el mismo Ortí (2010: 214), se centra en las dimensiones psíquicas, culturales y de clase de un sujeto típico de un grupo social de referencia. Las reacciones sociolibidinales en el marco de una investigación sociológica deberían tomarse como aspectos ideal-típicos que emergen en un momento determinado como elementos comunes entre sujetos y cristalizan en discursos compartidos. En ningún caso responderían a las características de cada individuo considerado en su global e idiosincrática individualidad ni a supuestas psicopatologías de éstos (Tizón, 2018b: 141). No sería necesario ni veraz, entendido así, afirmar un carácter específico, homogéneo y fijado por la socialización primaria para todos y cada uno de los individuos de un grupo social. Se trataría más bien de tendencias o reacciones proyectivas, emocionales y comunicativas típicas y compartidas en una misma situación o contexto socialmente definido. 
El contenido de estos modos de relación afectiva podría ser común en diferentes posiciones sociales, o bien distinto e incluso variable y ambivalente para un sujeto o varios miembros de una posición social, en función del contexto y del objeto de referencia. Un ejemplo del primer caso sería la dinámica depresiva del discurso ideológico en obreros y clases medias sobre el desencanto de la transición española y la crisis económica en los 70-80 (Ortí, 1985); o el modelo de paternidad generativa en padres de distintos grupos sociales (Kelly, 2018). Ejemplos del segundo los encontramos en estudios socio-motivacionales de consumo o en análisis de conflictos políticos, entre otros campos de estudio. Son habituales las cargas afectivas orales y anales (u de otro tipo) que refieren a componentes distintos de una misma imagen de marca/producto para los mismos consumidores (Ortí, 1979; Barbeta Viñas, 2015a); se analizan también reacciones diferenciales, oral-masoquistas y sádico-depresivas, ante campañas publicitarias en consumidores que comparten posición social (Ortí, 1984). Reacciones afectivas compartidas ante conflictos entre grupos grandes, conflictos bélicos, etc. se encuentran en Volkan (2018).

El modelo sociolibidinal se definiría entonces como un proceso dinámico producto de una compleja relación de procesos socioestructurales, simbólicoculturales y afectivos. Un proceso de respuesta y reacción vivencial a cada entramado contextual. Así la perspectiva sociológica, que aborda los fenómenos desde su interés por la estructura y la situación social, se articularía con una preocupación fundamental del psicoanálisis, que sería según Bofill y Tizón (1994: 102), "la comprensión de los elementos orales, anales, fálicos, etc. de un modo de relación cualquiera". 
Figura 2. Proceso de articulación sociolibidinal del sentido de los fenómenos sociales

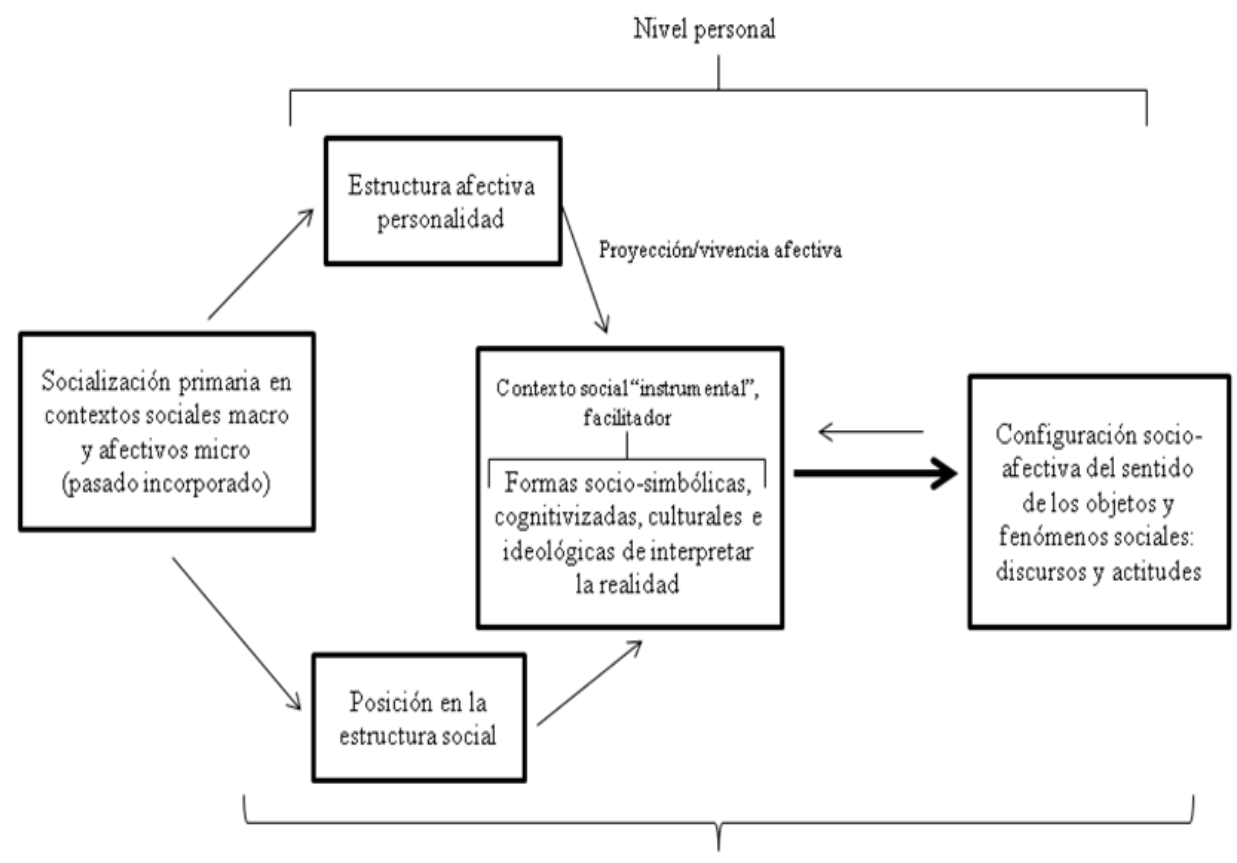

Fuente: Elaboración propia

Nivel social

\section{APUNTES ACERCA DEL ANÁLISIS SOCIOPSICOHERMENÉUTICO}

El carácter teórico y abstracto del modelo de los tipos sociolibidinales cuyas bases fundamentales se han presentado hasta aquí suele aplicarse en el marco de un enfoque constructivista concreto (Alonso, 1998). Su utilidad metodológica consiste en la configuración ad hoc de modelos teóricos en el seno de investigaciones empíricas. El contexto metodológico específico en el que se ha desarrollado la propuesta de los tipos sociolibidinales ha sido el representado por el análisis sociológico del discurso. Como hemos avanzado, la propuesta de Ortí podría entenderse como una ampliación de la orientación sociohermenéutica. Lo que se va a desarrollar a continuación debe inscribirse dentro de esta tradición cualitativa.

La aplicación del modelo sociolibidinal seguiría un lógica fundamentalmente heurística. Ello supone un procedimiento de análisis que debería permitir, por 
una parte, descubrir nuevos elementos relativos al cómo y porqué de determinados fenómenos sociales; y por otra, la solución de problemas pragmáticos y la cobertura de objetivos vinculados a una investigación concreta (Abbott, 2004).

El punto de partida sería tomar un corpus textual determinado como material empírico de base, una vez desarrollada una adecuada transcripción (Requena et al., 2018). La producción textual -de datos empíricos- en ciencias sociales en investigaciones donde se usa el modelo sociolibidinal se ha realizado mediante grupos de discusión, entrevistas abiertas y análisis documental (textos históricos, publicidad, etc.). Es abundante la literatura sobre la pertinencia de la entrevista para investigar el espacio de la subjetividad y sus aspectos afectivos, así como las formas sociales de una estructura de la personalidad (Figlio, 2018; Alonso, 2015; Ortí, 2010). El caso del grupo de discusión tiene la virtud, además, de contar con las influencias de las teorías psicoanalíticas del grupo (Bion, Käes) en su aplicación a la investigación sociológica (Ibáñez, 1979; Ortí, 2014). No son pocas las experiencias que ilustran las articulaciones de los aspectos afectivos y la producción discursiva en grupos de discusión. Por ejemplo, el supuesto básico de dependencia y las vivencias masoquistas, típicas entre los jornaleros y agricultores españoles en los años 70 y 80, en plena crisis del "campo" español (González et al., 1984). O bien el discurso de la pequeña burguesía castellana del año 1980, en plena crisis de gobierno de la UCD, estructurado -en el supuesto de ataque-fuga- como un delirio paranoide de persecución (de Lucas, 1980).

En cuanto al trabajo de análisis, la sociopsicohermenéutica no centraría su interpretación en las características psicológicas e individuales del "autor" o "autores" del texto (Ricoeur, 1995). Pondría su atención en los hablantes y las condiciones sociales y afectivas de la producción discursiva, en línea con los postulados del análisis del discurso (Sarfati, 1997). Esto implicaría dilucidar cómo los marcos sociales cristalizan en discursos sociales que, a través de sus expresiones verbales y simbólicas, son capaces de evocar y orientar deseos y reacciones afectivas (Ortí, 2010; Salling y Leithäuser, 2018; Charaudeau, 2011; Ricoeur, 1975).

La aproximación a los textos seguiría un planteamiento de análisis integral, es decir, un abordaje "literal" del conjunto del corpus, antes del trabajo de segmentación del material empírico (Conde, 2009). La tarea analítica, además, no solo se centraría en el análisis verbal, sino también en lo no verbal. Importarían las palabras dichas, pero también las no dichas, los silencios e incluso -cuando su registro lo posibilita- el análisis de los elementos gestuales y tonales de cuerpo y voz de los hablantes (Corin, 2012; Callejo, 2014).

La tarea de análisis interpretativo encontraría en el paradigma indiciario y el método abductivo de Ginzburg y Pierce unas bases adecuadas para su procedimiento (Tavory y Timmermans, 2014). Ésta consistiría, a grandes rasgos, en identificar en los textos empíricos las huellas, los indicios, las pistas, incluso los síntomas, que permitan analizar el sentido de los discursos y formular hipótesis interpretativas concretas acerca de la génesis social y afectiva del mismo. La reconstrucción del sentido pasaría por una tarea de codificación de los elementos empíricos (indicios...) y una posterior categorización teórico-empírica. La 
identificación y agrupamiento de los elementos empíricos dispersos en los textos generaría puntos categoriales que responderían teóricamente a unas u otras dinámicas sociolibidinales. Para la elaboración de las hipótesis sería conveniente que los indicios aparecidos en los textos formen sistema entre sí; es decir, que se refuercen unos a otros reduciendo el número de hipótesis posibles (Eco, 2013: 124).

Con la aplicación de este modelo al análisis sociológico del discurso pueden establecerse dos líneas complementarias de análisis: el referido al plano del contenido y al de la forma (Barthes, 1967: 38-58). El primero atendería a los significados (contenidos comunicativos), mientras que el segundo a los significantes (formas expresivas) del texto. Así se aborda qué se dice y cómo se dice, posibilitando la sistematización estructural, socio-simbólica, del discurso relativo a un objeto de estudio, y con ella la diferenciación de cargas afectivas vinculadas a los símbolos (palabras, expresiones) del discurso (Ortí, 2014).

Esta doble vía puede enriquecer particularmente las dimensiones socio-afectivas del análisis de los espacios semánticos y las posiciones discursivas (Conde, 2009). Ello posibilitaría el análisis de imágenes de objetos o procesos sociales, las actitudes ante los mismos, así como la relación del uso de símbolos, palabras concretas, con las proyecciones afectivas que éstas consiguen evocar, así como la identificación (o rechazo) de los hablantes con ellas. Entre los procedimientos con mayor rendimiento analítico para el enfoque sociolibidinal estarían también el análisis de las asociaciones, desplazamientos y condensaciones, adaptando su sentido psicoanalítico al análisis sociológico, así como algunos tipos concretos de emergentes discursivos (Conde, 2009: 233-240; 2019).

De acuerdo con lo anterior, en una investigación sociológica la aplicación de las categorías teóricas de los tipos sociolibidinales suele derivar del trabajo de análisis de los discursos, no antes a modo de hipótesis deductivas. Dichas categorías deben desarrollarse en el seno de determinados perfiles sociológicos que el investigador ha diseñado intencionalmente para la muestra. De esta forma la dinámica socio-afectiva que debe analizarse en los discursos queda vinculada a posiciones estructurales relacionadas con un objeto de estudio y establecidas en el diseño de la muestra (Castro Nogueira y Castro Nogueira, 2001).

El planteamiento de diseños concretos para estudiar fenómenos sociales concretos pide la definición de un campo social determinado (Bourdieu, 2000: 112-120). Ello implica que las categorías sociolibidinales utilizadas en el modelo resultante de un análisis deben entenderse como relativas a ese mismo campo objeto de estudio, pudiéndose articular en cada campo una dinámica sociolibidinal específica. Se trataría así de establecer correspondencias entre categorías teóricas y datos empíricos que adquirirían validez y sentido para un campo concreto, dado el carácter sistemático e interdependiente de los campos y contextos sociales (Lahire, 2012), así como la posibilidad de reacción afectiva más o menos distinta de los sujetos en los mismos. La comparación de lógicas sociolibidinales entre campos supondría, en algunas ocasiones, cierta repetición de categorías teóricas. Asimismo, un análisis diacrónico de un campo específico podría revelar el desplazamiento de simbolizaciones afectivas determinadas de 
un campo a otro. Todo ello respondería a la plasticidad afectiva o libidinal del sujeto humano. Si los elementos genéticos de los procesos afectivos son limitados (el abanico de emociones no es infinito), la riqueza socio-simbólica donde toman expresión es abierta y prácticamente inacabable (polimorfismo).

Lo anterior se observa con claridad en las investigaciones sobre consumo. Por ejemplo, la delimitación de un campo puede coincidir con un segmento de productos/marcas y/o consumidores. En el campo de las bebidas refrescantes, señala Ortí, la Pepsi-cola representaba a finales de los 60 en España una imagen oralizada y vinculada a las clases medias-bajas. Una imagen afectiva parecida a la del brandy Etiqueta Blanca 103 dentro del campo de las bebidas alcohólicas, así como la imagen turística de España por las clases trabajadoras inglesas (Ortí, 1979). Ello significa que símbolos (discursos) distintos en campos distintos pueden generar reacciones afectivas similares, aunque la contextualización social y significativa específica de cada imagen puede contribuir a establecer diferencias mayores o menores entre una dinámica socioafectiva y otra. La oralidad dentro del campo de las bebidas alcohólicas es mucho más relativa que en las bebidas refrescantes que, en principio, por sus características organolépticas y su forma de consumo condensan de forma más evidente las características propias de las relaciones orales.

En cuanto a la perspectiva diacrónica, si la marca La Lechera simbolizaba la oralidad de la "madre buena" y un alimento de "gran calidad" entre la clase media española entre los 50 y los 70 , estas proyecciones han sido encarnadas actualmente en similar posición social por el consumo ecológico (Barbeta Viñas, 2015a). Cambio de campo y segmento de las proyecciones afectivas "orales y maternales" que puede vincularse a la transformación de los hábitos dietéticos y su identificación con el papel de la "buena madre": la leche condensada ya no es en el imaginario colectivo de las clases medias el alimento de "calidad" que las "buenas madres" usan para nutrir y alimentar a los más pequeños. Para otros ejemplos como la evolución de la moda: véase Infante (1994).

En cuanto al proceso de interpretación, el modelo sociolibidinal atiende a los niveles latente y/o profundo del discurso. Ello nos remite a la indagación del nivel preconsciente del sentido de los discursos en el primer caso, y del inconsciente en el segundo (Ortí, 2010). En ambos niveles, la interpretación sociopsicoanalítica debe entenderse como analogía y buscando siempre los modos de articulación entre lo afectivo y lo social (Alonso, 1998: 63). Entre las aportaciones de Ortí y otros sociólogos está, justamente, la proyección de los tipos sociolibidinales en el preconsciente, entendido como el lugar de cristalización de lo social, el lenguaje y la ideología en los sujetos (Barbeta Viñas, 2015c). Las interpretaciones sobre lo preconsciente, derivadas de material asociativo no consciente, proceden mediante una lógica inferencial (o deducción) sobre el sentido, pudiendo quedar validadas de acuerdo con los criterios de: a) inteligibilidad y capacidad explicativa del fenómeno en cuestión, b) plausibilidad con la realidad, c) aceptabilidad, d) coherencia teórica con el modelo de referencia y e) compatibilidad con el estado de conocimiento existente, y g) mayor probabilidad respecto a hipótesis alternativas (Morse, 2003; Ricoeur, 1995). 
Las interpretaciones referidas a procesos inconscientes son más arriesgadas y difícilmente contrastables en un análisis sociológico. Así se suele apelar a la validación pragmática de sus conclusiones, como ha ocurrido en investigaciones de consumo y publicidad (Ortí, 1984). Sin embargo, contribuciones recientes presentan herramientas para la operativización de elementos afectivos e inconscientes orientadas al análisis social (Stamenova y Inshelwood, 2018).

Añadiremos que el trabajo de interpretación mediante el modelo sociolibidinal requiere, además de un componente lógico-formal y teórico, un momento que podríamos llamar intuitivo-empático (Coderch, 1995: 70-77). El primer componente sería necesario, como en cualquier investigación, para avanzar en el proceso de elaboración teórica del material empírico, para el desarrollo conceptual y cognitivo de los resultados de una investigación. El modelo teórico sociolibidinal serviría, al fin, para encauzar y delimitar las primeras conjeturas en las que la intuición y la empatía adquieren un papel relevante; tal vez más en este caso donde se propone interpretar la dimensión afectiva de procesos sociales. Como señalaba Weber (1922: 7), un cierto grado de empatía, de identificación con aquellos que hablan, así como el desarrollo de algunas intuiciones pueden ser útiles para conectar con el tono emocional de los hablantes, orientar las comunicaciones libradas por éstos con sus discursos y, finalmente, elaborar de forma intuitiva y provisional unas primeras hipótesis. ${ }^{5}$

\section{CONCLUSIONES}

El modelo sociolibidinal creado por Alfonso Ortí propone una articu-lación concreta entre elementos de la sociología y el psicoanálisis. Se trata de una propuesta que, a diferencia de otras, sitúa en el centro del análisis los afectos y la relación dialéctica que existe entre la persona y sus distin-tos entornos sociales. El enfoque sociolibidinal se construye como modelo de interpretación de los procesos sociales desde la perspectiva del sentido. Un sentido que se define sobredeterminadamente como social y personal a la vez. A nivel subjetivo el sentido nos remite al deseo, a las posiciones y reacciones afectivas vinculadas a la personalidad. A nivel social, lo hace a los procesos intersubjetivos, culturales e históricamente condicionados, así como a las realidades materiales objetivas en las que sujetos y grupos están insertos. Este nivel social es el que en nuestra perspectiva metodoló-gica tiende a condicionar, moldear y posibilitar el desarrollo común de los componentes afectivos subjetivos que, en determinados contextos, pasan a ser intersubjetivos y simbólicos.

${ }^{5}$ Existe el debate sobre la necesidad del sociólogo de haber realizado algún tipo de psicoterapia (de orientación psicoanalítica), entendiendo con ello que así se ganaría autoconocimiento y experiencia que puede ser de utilidad en el análisis cualitativo con influencias psicoanalíticas. Más allá de la estricta necesidad, puede que favorezcan unas interpretaciones más ricas y contraladas. El trabajo en grupo puede ser también un buen modo de controlar las sobreinterpretaciones. 
Entre las virtudes del enfoque presentado está su carácter pragmático orientado a la investigación empírica. En este caso la aplicación del psicoanálisis no nos lleva hacia elevados rodeos teóricos sin contacto con la realidad empírica. En cuanto que modelo interpretativo, el enfoque sociolibidinal se construye en la praxis investigadora y encuentra su correlato real y concreto, como todo análisis hermenéutico del discurso, en los lími-tes objetivos que proporcionan los datos empíricos con los que trabaja: los textos. Aquí solo esbozamos algunos aspectos generales relacionados con la aplicación teóricometodológica del modelo en el marco del análisis sociológico del discurso. Su análisis en profundidad de las herramientas y criterios de análisis puede ser, sin duda, una tarea a desarrollar en futuros trabajos.

Cabría señalar elementos que podrían ampliar el potencial teórico y metodológico de la perspectiva. Por ejemplo, 1) reflexionar sobre una posible articula-ción, a la luz de la presente propuesta, con los análisis que refieren a subjetivida-des históricas como ocurre con la esquizofrenia y la posmodernidad (Jameson), lo depresivo en los 70's (Ehrenberg), o la personalidad neurótica (Horney), entre otras. 2) Cuestionar la transformación histórica de fenómenos sociopolíticos y su relación con lo afectivo. Ortí (1991: 503) señala unas dinámicas libidinales específicas en el populismo, así como en la génesis motivacional del fascismo y el comunitarismo igualitario. ¿Pueden pensarse estos fenómenos tal como se presentan actualmente mediante las mismas lógicas sociolibidinales que podían desarrollar en sus contextos sociales de origen? 3) Podrían explorarse también otras vías de articulación entre los componentes afectivos y los socio-culturales: los trabajos de John Bowlby sobre el apego, escasamente utilizados en CCSS, así como la señalada incorporación de los prototipos de la personalidad relacionados con las posiciones y fases antes presentadas (Tizón, 2018b y 2019a; Rodríguez Sutil, 2014).

No podemos concluir sin señalar que los usos del modelo sociolibidinal realizados hasta hoy ponen de manifiesto su fecundidad pragmática en el marco de investigaciones concretas. Los análisis sociolibidinales se han mostrado reveladores de dinámicas socioafectivas y motivacionales que, de otra forma, difícilmente hubieran podido ser evidenciadas como lo muestran los trabajos citados de Ortí y otros autores próximos.

\section{BIBLIOGRAFÍA}

ABBOTT, A. (2004): Methods of Discovery: Heuristics for the Social Sciences, New York: W.W. Norton.

ALONSO, L.E. (2015): "La entrevista abierta como práctica social”. En: García FERRANDO, M. et al. [comps.] El análisis de la realidad social. Métodos y técnicas de investigación. Madrid: Alianza $4^{\mathrm{a}}$ ed.

ALONSO, L.E. (2013): "La sociohermenéutica como programa de investigación en sociología”. Arbor, 189 (761). http://dx.doi.org/10.3989/arbor.2013.761n3003. 
ALONSO, L.E. (1998): La mirada cualitativa en sociología. Madrid:

Fundamentos.

BARBETA VIÑAS, M. (2015a): "Entre renúncies, temors i deures: Anàlisi de l'estructura motivacional del consumo ecològic". Papers, revista de sociologia, 100(1):5-33.

BARBETA VIÑAS, M. (2015b): "El símbolo da qué pensar: esbozo para una teoría psicosociológica del simbolismo. Perspectiva cognitivo-afectiva, discurso e interpretación”. Sociológica, 30 (85):163-196.

BARBETA VIÑAS, M. (2015c): "Sociología y preconsciente freudiano: el nivel latente del análisis del discurso ideológico". Empiria: Revista de Metodología de Ciencias Sociales, 31:97-129.

BATEMAN, A. y FONAGY, P. (2012): Handbook of Mentalizing in Mental Health Practice. Londres: American Psychiatric Publishing.

BARTHES, R. (1967): Elementos de semiología. Madrid: Alberto Corazón.

BELTRÁN, M. (2016): Hermenéutica y dramaturgia: para entender la realidad social, Madrid: CIS.

BERGER, P. L. y LUCKMANN, Th. (1967): La construcción social de la realidad, Buenos Aires: Amorrortu.

BERICAT, E. (2016): "The sociology of emotions: Four decades of progress". Current Sociology, 63(3): 491-513

BLACKMAN, L. y VENN, C. (2010): “Affect”. Body and Society, 16(1): 7-28.

BOFILL, P y TIZÓN, J. (1994): Qué es el psicoanálisis: orígenes, temas e instituciones actuales. Madrid:Herder.

BOURDIEU, P. (2000): Cuestiones de sociología. Madrid: Istmo.

BOURDIEU, P. (1991): El sentido práctico. Madrid: Taurus.

BROWN, N. (1959): Eros y Thanatos. El sentido psicoanalítico de la historia, Barcelona: Santa \& Cole.

BUTLER, J. (2006): Deshacer el género. Barcelona: Planeta

CALLEJO, J. (2014): "Bosquejo para la observación de la emoción en los procesos sociales”, Revista Internacional de Comunicación y Desarrollo, 1:91-102.

CASTRO NOGUEIRA, L. y CASTRO NOGUEIRA, M. Á. (2001): "Cuestiones de metodología cualitativa", Empiria, Revista de metodología de ciencias sociales, 4: 165-192.

CHANCER, L. y ANDREWS, J. (2014): The Unhappy Divorce of Sociology and Psychoanalysis:Diverse Perspectives on the Psychosocial. Basingstoke: Palgrave.

CHARAUDEAU, P. (2011): "Las emociones como efectos de discurso", Versión, 26: 97-118.

CLARKE, S. (2006): “Theory and practice: psychoanalytic sociology as psycho-social studies". Sociology, 40(6): 1153-1169.

CODERCH, J. (2010): La práctica de la psicoterapia relacional. El modelo interactivo en el campo del psicoanálisis, Madrid: Ágora Relacional.

CODERCH, J. (1995): La interpretación en psicoanálisis. Fundamentos y teoría de la técnica. Madrid: Herder.

CONDE, F. (2019): "Apuntes sobre el análisis y la interpretación de los "emergentes discursivos' en el análisis de los discursos". Encrucijadas: Revista Crítica de Ciencias Sociales, 17.

CONDE, F. (2009): Análisis sociológico del sistema de discursos. Madrid: CIS.

CORIN, E. (2012): “Commentary: Interdisciplinary Dialogue: A Site of

Estrangement”. Journal of Society for Psychological Anthropology, 40(1):104-112. 
DAMASIO, A. (2018): El extraño orden de las cosas: la vida, los sentimientos y la creación de las culturas. Barcelona: Destino.

DELEUZE, G. (1967): Presentación de Sacher-Masoch. Lo frío y lo cruel. Buenas Aires: Amorrortu, 2001.

DEVEREUX, G. (1972): Etnopsicoanálisis complementarista. Buenos Aires: Amorrortu.

ECO, U. (2013): Los límites de la interpretación. Barcelona: Debolsillo.

ELÍAS, N. (1990): La sociedad de los individuos. Madrid: Península.

ERIKSON, E. (1963): Infancia y Sociedad. Buenos Aires: Hormé.

FIGLIO, K. (2018): “A psychoanalytic view of qualitative methodology. Observing the elemental psychic world in social processes". En: STAMENOVA, K. y HINSHELWOOD, R. (eds.) Methods of Research into the Unconcious. Appliyng Psychoanalytic ideas for Social Sciene. NY:Routledge.

FREUD, S. (1923): "El yo y el ello". En: Obras Completas. Buenos Aires: Amorrortu, 1986.

FREUD, S. (1908): "El carácter y el erotismo anal”. En: Obras Completas. Buenos Aires: Amororrtu, 1986.

FREUD, S. (1905): “Tres ensayos de teorías sexual". En: Obras Completas. Buenos Aires: Amororrtu, 1986.

FROMM, E. (1976): Marx i Freud. Barcelona: Edicions 62.

FROMM, E. (1977): La por a la llibertat. Barcelona: Edicions 62.

FURTH, H. (1992): El conocimiento como deseo. Un ensayo sobre Freud y Piaget, Madrid: Alianza Editorial.

GEERTZ. C. (1973): La interpretación de las culturas. Barcelona: Gedisa.

GERTH, H. y WRIGHT MILLS, Ch. (1984): Carácter y estructura social: la psicología de las instituciones sociales. Barcelona: Paidós.

GONZÁLEZ, J. J.; DE LUCAS, Á. y ORTÍ, A. (1984): Sociedad rural y juventud campesina. Madrid: IEAPA.

IBÁÑ̃EZ. J. (1979): Más allá de la sociología: el grupo de discusión: teoría y crítica. Madrid: Siglo XXI.

INFANTE, L. (1994): "Lencería Blanca interior (de la Gradación a la Colección)”. Política y Sociedad, 16: 191-200

KELLY, D. (2018): “Generative fatherhood and children's future civic engagement: A conceptual model of the relationship between paternal engagement and child's developing prosocial skills". Journal of Human Behavior in the Social Environment, 28(3):303-314.

KLEIN, M. (1946): “Notas sobre algunos mecanismos esquizoides" En: Desarrollos en psicoanálisis. Buenos Aires: Hormé, 1967.

KLEIN, M. (1957): “Envidia y Gratitud”. En: KLEIN, M. y RIVIERE, J. Amor, odio y reparación: emociones básicas del hombre. Buenos Aires: Hormé, 1968.

LAHIRE, B. (2012) : Monde pluriel. Penser l'unité des sciences sociales. París: Seuil.

LONG, S. y HARNEY, M. (2013): “The associative unconscious”. En: LONG, S. Socioanalytic Methods. London: Karnac (pp. 3-22).

LAPLANCHE, J. y PONTALIS, J.-B. (1993): Diccionario de psicoanálisis.

Barcelona: Paidós.

LORENZER, A. (1976): Crítica del concepto psicoanalítico de símbolo. Buenos Aires: Amorrortu.

LORENZER, A. (1972): Bases para una teoría de la socialización. Buenos Aires: Amorrortu. 
LUCAS, DE Á. (1980): Investigación Cualitativa Continua sobre la situación política, económica y social en Castilla la Mancha (inédito).

MILLON, Th. y DAVIS, R. (1999): Trastornos de la personalidad. Más allá del DSM$I V$. Barcelona: Masson.

MORSE, J. (2003): Asuntos críticos en los métodos de investigación cualitativa, Alacant: Publicaciones Universitat d'Alacant.

ORTÍ, A. (2014): "Encuestación cualitativa y praxis socioinstitucional: de la configuración de subjetividades sociales a la de discursos virtuales". Arxius de Ciències Socials, 31: 27-56.

ORTÍ, A. (2010): "La apertura del enfoque cualitativo o estructural: la entrevista abierta semidirectiva y la discusión de grupo". En GARCÍA FERANDO, M. et al. [comps.] El análisis de la realidad social. Métodos y técnicas de investigación. Madrid: Alianza $3^{\mathrm{a}}$ ed.

ORTÍ, A. (1998): “Libido”. En: GINER, S. et al., Diccionario de Sociología, Madrid: Alianza.

ORTÍ, A. (1994): "La estrategia de la oferta en la sociedad neocapitalista de consumo: Génesis y praxis de la investigación motivacional de la demanda". Política y Sociedad, 16: 37-92.

ORTÍ, A. (1993): "El proceso de investigación de la conducta como proceso integral: complementariedad de las técnicas cuantitativas y de las prácticas cualitativas en el análisis de las drogodependencias". En: VVAA, Las drogodependencias: perspectivas sociológicas actuales. Madrid: CNDLPS.

ORTÍ, A. (1991): "Génesis antiologárquica y ambiguedad política de los populismos: entre el comunitarismo igualitario y la reconversión fascista”. En: CASTILLO, S. [coord.] La historia social de España: actualidad y perspectivas. Madrid: Siglo XXI.

ORTÍ, A. (1985): Ideologías: Una aproximación a las representaciones cotidianas sobre la evolución social, Vol.1. CIMOP, inédito.

ORTÍ, A. (1984): Informe post-test motivacional “Long John”. Madrid: CELSA, inédito.

ORTÍ, A. (1979): "Motivaciones turísticas europeas e imagen turística de España 1977: un enfoque cualitativo". Revista de Estudios Turísticos, 63/64 (3/4): 5-123.

ORTÍ, A. (1975): "Estudio introductorio". En: COSTA, J. Oligarquía y caciquismo como la forma actual de gobierno en España: urgencia y modo de cambiarla. Madrid: Revista de Trabajo, Tomo I.

PANKSEPP, J. y BIVEN, L. (2012): The Archeology of Mind: Neuroevolutionary Origins of Human Emotions. NY: Norton.

PASQUALINI, M. (2016): Psicoanálisis y teoría social. Inconsciente y sociedad de Freud a Zizek. Buenos Aires: FCE.

REQUENA, M.; GÓMEZ, E y MUÑOZ-RODRÍGUEZ, D.(2018). "El fetichismo de la transcripción: Cuando el texto pierde el lenguaje analógico". Empiria, Revista de Metodología de Ciencias Sociales, 39: 79-101.

RICOEUR, P. (1995): Teoría de la interpretación. Discurso y excedente de sentido. México: Siglo XXI.

RICOEUR, P. (1975): Hermenéutica y Estructuralismo. Buenos Aires: Megápolis.

RODRÍGUEZ SUTIL, C. (2014): Psicopatología psicoanalítica relacional. La persona en relación y sus problemas. Madrid: Ágora Relacional.

SARFATI, G. (1997): Élements d'analyse du discours. Paris: Armand Colin. 
SALLING, H. y LEITHÄUSER, Th. (2018): "Psychosocial interpretation of unconcious dimensions in everyday life". En: STAMENOVA, K. y HINSHELWOOD, R. (eds.) Methods of Research into the Unconcious. Appliyng Psychoanalytic ideas for Social Sciene. NY:Routledge.

STAMENOVA, K. y HINSHELWOOD, R. (eds.) (2018). Methods of Research into the Unconcious. Appliyng Psychoanalytic ideas for Social Sciene. NY:Routledge.

STETS, J. y TURNER, J. (Eds.) (2006): Handbook of the Sociology of Emotions. NY: Springer.

TAVORY, I. y TIMMERMANS, S. (2014): Abductive Analysis: Theorizing Qualitative Research. Chicago: University of Chicago.

TIZÓN, J. (2019a): Apuntes para una psico(pato)logía basada en la relación, Vol.3. Relaciones emocionalizdas, intrusivas, actuadoras y operatorias. Barcelona: Herder.

TIZÓN, J. (2018b): Apuntes para una psico(pato)logía basada en la relación, Vol.2. Relaciones Dramatizadas, Atemorizadas y Racionalizadoras. Barcelona: Herder.

TIZÓN, J. (2018a): Apuntes para una psico(pato)logía basada en la relación, Vol.1. Barcelona: Herder.

TIZÓN, J. (1982): Apuntes para una psicología basada en la relación. Barcelona: Herder.

VOLKAN, V. (2018). Psicología de la sociedades en conflicto. Barcelona: Herder.

WEBER, M. (1922): Economía y sociedad. Esbozo de una sociología comprensiva. México: FCE, 1964.

WILLIAMS, R. (1994): Sociología de la cultura. Barcelona: Paidós. 
Copyright of EMPIRIA: Revista de Metodología de Ciencias Sociales is the property of Editorial UNED and its content may not be copied or emailed to multiple sites or posted to a listserv without the copyright holder's express written permission. However, users may print, download, or email articles for individual use. 